IX Congresso Brasileiro de Informática na Educação (CBIE 2020)

Anais do XXXI Simpósio Brasileiro de Informática na Educação (SBIE 2020)

\title{
Articulando estudos nas áreas de Design da Aprendizagem, Design Thinking $e$ Canvas, para a proposição de currículos baseados em competências
}

\author{
Gabrielle dos Santos ${ }^{1}$, Patrícia Scherer Bassani ${ }^{1}$
}

\author{
${ }^{1}$ Programa de Pós-Graduação em Diversidade Cultural e Inclusão Social \\ Universidade Feevale - RS - Brasil \\ \{gabrielle, patriciab\} @feevale.br
}

\begin{abstract}
This paper aims to contribute and broaden the scope of research in the area of Learning Design, presenting a methodological approach to guide the design of undergraduate courses, based on learning by competences, articulating studies in the Design Thinking area and inspired by the visual perspective proposed by the Business Model Canvas. The study, based on an applied and qualitative approach, was conducted through Design Science Research. As a result, we present a methodology organized in three stages: Reflective / immersive (game of ideas); Planning ideation; Prototyping. The validation process was conducted in the context of higher education.
\end{abstract}

Resumo. Este artigo busca contribuir e ampliar o escopo de pesquisas na área de Design da Aprendizagem, apresentando uma proposta metodológica para orientar a concepção de cursos de graduação, com base na aprendizagem por competências, articulando estudos da área Design Thinking e buscando inspiração na perspectiva visual proposta pelo Business Model Canvas. A metodologia, de natureza aplicada e de abordagem qualitativa, foi conduzida por meio da Design Science Research. Como resultado, apresentamos uma metodologia organizada em três etapas: Reflexiva/imersiva (jogo de ideias); Ideação do planejamento; Prototipação. O processo de validação foi conduzido no contexto do ensino superior.

\section{Introdução}

O Design da Aprendizagem (ou Learning Design) é uma área de estudos que busca "tornar o processo de desenvolvimento de atividades de aprendizagem com o uso de tecnologias mais explícito" (BASSANI, 2014). Estudos na área de Design da Aprendizagem (DA) se organizam por meio de três linhas de pesquisa complementares: orientação (guidance), representação (representation) e compartilhamento (sharing). $\mathrm{O}$ DA foca na formação de professores e/ou profissionais da educação, para a concepção, o registro e o compartilhamento de atividades de aprendizagem. Existem diferentes ferramentas e métodos que podem ser usados para orientar os professores no processo de criação/proposição de atividades de aprendizagem (BASSANI, 2014, SANTOS; BASSANI, 2020). Além disso, existem diferentes ambientes on-line que possibilitam o compartilhamento dessas atividades, para que os professores possam ter acesso a diferentes ideias (BASSANI et al., 2019).

Portanto, o DA oportuniza formas de representar as atividades de aprendizagem permitindo que elas sejam compartilhadas. Pode-se representar diferentes níveis de 
granularidade, envolvendo desde uma atividade individual até a concepção de um curso (CONOLE, 2013).

Diferentes modelos podem ser usados para conduzir o processo de concepção de um novo curso. Conole (2013) faz uma compilação de várias propostas, envolvendo desde o uso de um course map (ou mapa de curso) descritivo até o uso de ferramentas como o CompendiumLD ((http://compendiumld.open.ac.uk/). Pesquisas realizadas por Conole (2013), envolvendo a avaliação do CompendiumLD com professores, mostraram que a representação visual de uma atividade de aprendizagem possibilita a compreensão da estrutura geral da proposta e o compartilhamento de ideias. Entretanto, esse conjunto de propostas (métodos, recursos e ferramentas) estão disponíveis apenas em língua inglesa, o que pode inviabilizar o engajamento dos professores no processo (BASSANI, 2014; BASSANI; LIMA; DALANHOL, 2016, BASSANI et al, 2019, SANTOS; BASSANI, 2020).

Este artigo busca contribuir e ampliar o escopo de pesquisas na área de DA, apresentando uma proposta para orientar a concepção de cursos de graduação, articulando estudos da área de DA e Design Thinking, e buscando inspiração na perspectiva visual proposta pelo Business Model Canvas.

O Design Thinking (DT) é uma abordagem que apresenta o design como uma possibilidade de "tornar tangível uma intenção de transformação" (NITZSCHE, 2012), buscando transformar problemas reais em soluções simples e assertivas. Assim, entendemos que o DT pode ser utilizado como método de condução de um processo de planejamento curricular/modular.

Também buscamos inspiração no Business Model Canvas, mais conhecido como Canvas. O Canvas é um modelo que foi desenvolvido para a área de negócios. Entretanto, estudos na área da Educação já vem mostrando que modelos de Canvas, alinhados à metodologia de Design Thinking, podem ser utilizados na perspectiva do planejamento docente (RUIZ, 2019).

Desta forma, este artigo apresenta o percurso de validação de um processo desenvolvido para auxiliar os docentes na elaboração de módulos de aprendizagem em cursos de graduação. O processo foi inspirado nos estudos na área de DA e DT, tendo como inspiração a matriz de Canvas. Este estudo é um recorte de uma pesquisa em andamento no PPG em Diversidade Cultural e Inclusão Social, na Universidade Feevale.

O artigo está assim organizado: partimos de uma reflexão sobre o Design da Aprendizagem, Design Thinking e modelo Canvas, na seção 2. O percurso de pesquisa está detalhado na seção 3, seguido pela apresentação dos resultados (seção 4 ), discussão (seção 5) e, por fim, as considerações finais e referencias.

\section{Design da Aprendizagem, Design Thinking $e$ Canvas para a proposição de currículos baseados em competências}

O DA é uma área de pesquisa que começou a se fortalecer a partir de 2005 , focando no desenvolvimento de ferramentas, métodos e abordagens, que buscam auxiliar o professor no planejamento, na utilização e no compartilhamento de atividades de aprendizagem que façam uso efetivo das tecnologias digitais. O DA se organiza a partir de três pilares: orientação, representação e compartilhamento. Sob a perspectiva da orientação, tem por objetivo auxiliar os docentes na elaboração e na proposição de atividades de 
aprendizagem com tecnologias, envolvendo formação em tecnologias digitais e orientação no processo de planejamento dessas atividades. Sob a perspectiva da representação, foca no desenvolvimento e na proposição de modelos e/ou ferramentas para representar/documentar as atividades de aprendizagem. Por fim, sob a perspectiva do compartilhamento, visa disponibilizar as representações para que outros docentes possam ter acesso a diferentes ideias de práticas de ensino (THE LARNACA DECLARATION ON LEARNING DESIGN, 2013).

Este estudo se concentra no contexto da orientação, uma vez que envolve a proposição de um processo que irá auxiliar os docentes na concepção de cursos de graduação organizados por módulos de aprendizagem. Conforme pesquisas na área de DA, a orientação pode ser aplicada em diversas granularidades, desde atividades simples de estudo até currículos em cursos de graduação e pós-graduação. Em consonância, entendemos que a abordagem de Design Thinking (DT) pode ser utilizada para conduzir o processo de orientação.

Cavalcanti e Filatro (2016, p. 20) ressaltam que o DT "é composto de um processo, um modo de pensar, métodos e estratégias", bem como por recursos que, em grande maioria, são visuais e prezam por facilitar a comunicação e a resolução de ideias. Sua capacidade de avançar os níveis de forma gradativa e imperceptível e, ao mesmo tempo, propiciar a correção quando necessário e retomar os objetivos, é o ponto chave para sustentar grandes projetos e elevar o nível de acerto e criatividade.

O DT, além de ser explorado em diversas disciplinas na Universidade de Standford, também ganhou espaço no Instituto de Tecnologia de Massachusetts (MIT), em Boston, bem como na Universidade de Potsdam, em Berlim. Em 2009, a d.school ${ }^{1}$ publicou um guia chamado Bootcamp Bootleg, que vem sendo atualizado constantemente e está disponível em formato on-line. Esse guia busca disseminar as ferramentas e cases adotados no DT. Essas instituições de ensino vêm utilizando "o DT como estratégia de ensinoaprendizagem e construção de conhecimento pelo desenvolvimento de projetos colaborativos" (CAVANCANTI; FILATRO, 2016, p.27).

No campo educacional, o DT tem como premissa a inovação e se articula em três aplicações: a) estratégias de ensinoaprendizagem; b) metodologia para a solução de problemas; c) abordagem de inovação. Cabe destacar que soluções de respostas desejáveis e viáveis nesta área de estudo podem ter início em uma das aplicações, porém, muitas vezes, as soluções acabam por perpassar todos os elementos aplicáveis.

Também buscamos inspirações em matrizes de Canvas, para a construção do artefato. O modelo de Canvas teve sua gênese no mundo dos negócios, denominado Business Model Canvas, com a permissa de promover a construção de modelos de negócio de forma ágil e em uma única lauda, por isso seu nome, que vem do grego "Canvas" que significa "tela". Entretanto, o Canvas logo tomou outras finalidades e diversas variações em outras áreas do conhecimento, como a Educação, uma vez que visa facilitar a organização das ideias e o fluxo das ações de forma simples e visual (RUIZ, 2019), podendo ser feita de forma colaborativa e em pares.

${ }^{1}$ https://dschool.stanford.edu/ 
No contexto deste estudo buscamos propor um processo para orientar a condução do planejamento de um currículo de graduação organizado em módulos e baseado na perspectiva da aprendizagem por competências.

Estudos na área da educação apontam que a aprendizagem por competências é uma das formas mais completas e assertivas, pois parte do pressuposto de que o sujeito é capaz de resolver problemas complexos (ZABALA; ARNAU, 2020). Em uma perspectiva ampla, é a aprendizagem para a ação. Gutiérrez (2017) afirma que as competências são compostas por três pilares: a) saber; b) saber-fazer; c) saber-ser. A articulação harmônica desses pilares traduz, respectivamente, o conhecimento, a habilidade e a atitude.

Zabala e Arnau (2020) indicam que as competências são necessárias e tiveram origem diante da incapacidade que os alunos têm em aplicar as teorias aprendidas nas práticas do dia-a-dia. As competências vão para além da área acadêmica e/ou escolar. Ao encontro desta afirmação, os autores, destacam a necessidade do desenvolvimento de competências pessoais, interpessoais, bem como sociais, que são de extrema relevância para as situações-problemas da vida cotidiana. Zabala e Arnaus (2020, p.7) destacam, ainda, que o

ensino de competências implica assumir dois desafios: por um lado, a ampliação dos conteúdos de aprendizagem ligados ao saber fazer, saber ser e saber conviver; por outro, a necessidade de que as aprendizagens não se reduzam à memorização mas que possam ser aplicadas em qualquer circunstância da vida.

A aprendizagem por competências destaca a necessidade da aplicação dos conhecimentos em atividades práticas do dia-a-dia no fazer profissional e pessoal de cada sujeito. Nessa perspectiva, a memorização é a teoria descontextualizada e fora da prática reflexiva, e isso não compactua com uma competência necessária ao sujeito. Assim, a aprendizagem por competências "é considerada funcional não apenas pelo fato de possuir conhecimento, mas também, e especialmente, por comportar a capacidade de aplicá-lo em novas situações" (ZABALA; ARNAUS, 2020, p.8).

Perrenoud (2013), complementa dizendo que, ao longo da vida, o sujeito é colocado permanentemente a enfrentar diversos obstáculos que só serão possíveis se determinas competências, sejam elas acadêmicas, pessoais e/ou sociais, forem desenvolvidas. Zabala e Arnau (2020, p. 9) afirmam que "a competência consistirá na intervenção eficaz em diferentes áreas da vida, por meio de ações nas quais componentes atitudinais, procedimentais e conceituais são mobilizados, ao mesmo tempo e de forma inter-relacionada".

No que diz respeito ao processo de aprendizagem por competências, o conhecimento prévio do sujeito sempre é levado em consideração pois, a partir destas novas coordenações, são feitas e surgem novas conexões e novas aprendizagens. A aprendizagem contextualizada e significativa auxilia e torna o processo de aplicação dos conhecimentos apreendidos mais assertivo, e aumenta a possibilidade de novas relações, uma vez que as competências visam a formação integral do sujeito.

\section{Metodologia}

Este estudo é um recorte do projeto de pesquisa Práticas educativas em/na rede desenvolvido no Programa de Pós-Graduação em Diversidade Cultural e Inclusão Social 
(Universidade Feevale), que estuda um modelo de artefato de mediação para o registro e o compartilhamento de atividades de aprendizagem com uso de tecnologias digitais.

A pesquisa, de natureza aplicada e de abordagem qualitativa, foi conduzida por meio da metodologia Design Science Research (DSR). DSR é um método de pesquisa orientado para a solução de problemas, que busca minimizar o distanciamento entre a teoria e a prática. A DSR é indicada para pesquisas que têm por objetivo projetar e construir artefatos ou ainda prescrever soluções (DRESCH et al., 2015).

O processo de pesquisa foi conduzido a partir de quatro etapas (Figura 1): a) identificação do problema; b) identificação de artefatos semelhantes; c) proposição do artefato (processo); d) validação.

No contexto desta pesquisa, o artefato produzido se caracteriza por uma proposta para a concepção de cursos de graduação baseados em módulos de aprendizagem.

Os resultados das etapas de Identificação do Problema e Identificação dos Artefatos foram publicados em estudos anteriores (SANTOS; BASSANI, 2020). A análise desses resultados, aliada aos estudos na área de DA e DT, apoiados em Cavalcanti e Filatro (2016), Ruiz (2019), Bassani (2014), Bassani et al, 2016 e Bassani et al, 2019), além dos estudos na área de competências, conforme Zabala e Arnau (2020), balizaram a proposta aqui apresentada.

A validação da proposta foi conduzida com um grupo de docentes da área de Gestão, de uma universidade localizada no Vale dos Sinos/RS. Os resultados estão descritos na próxima seção.

Figura 1- etapas da pesquisa

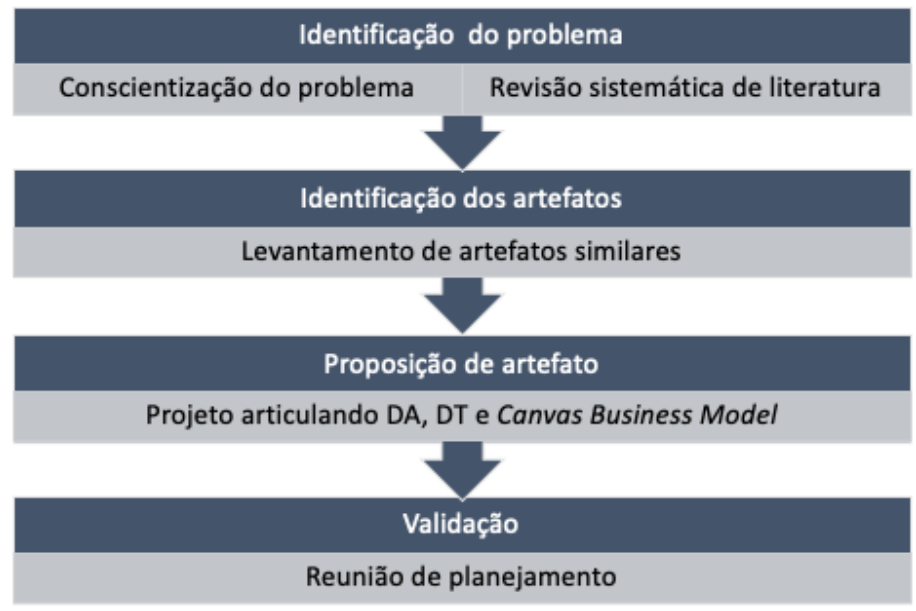

Fonte: elaborada pelas autoras (2020)

\section{Resultados}

A validação da proposta foi realizada com docentes de uma instituição de ensino superior, de forma on-line, devido ao momento de pandemia em que nos encontramos. A condução de todo o processo foi feita por vídeo chamada, na plataforma Microsoft Teams. Esta plataforma de webconferência foi escolhida, pois é usada amplamente na instituição. 
Nesse caso, a plataforma já era de conhecimento dos envolvidos e, assim, entendemos que poderia facilitar a condução do processo a distância. Entretanto, a mediação pode ser realizada em outro ambiente de webconferência, como Google Meet, por exemplo.

A validação foi feita com um módulo já existente de um curso de graduação na modalidade digital, da área de Gestão. Este módulo era composto por três componentes curriculares, sendo duas disciplinas e um projeto integrador. Participaram da validação dois professores da área, a equipe do Núcleo de Apoio ao Ensino e Aprendizado (NAEP) e a pesquisadora, como pedagoga e condutora do processo. A Figura 2 apresenta o registro da reunião.

Figura 2 - Reunião de condução do processo no ambiente Microsoft Teams

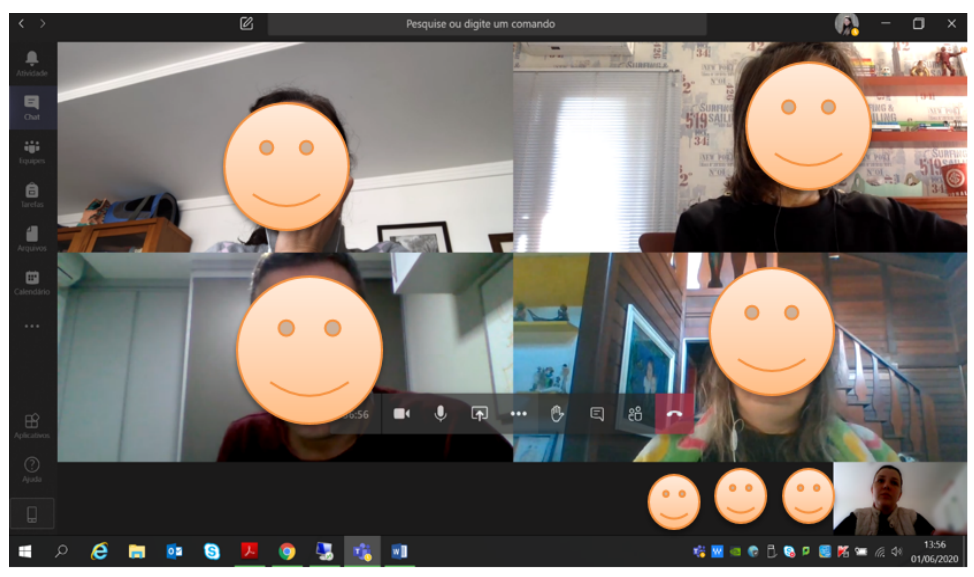

Fonte: acervo das autoras (2020)

A proposta desenvolvida foi organizada em três etapas: 1) Reflexiva/imersiva (jogo de ideias); 2) Ideação do planejamento; 3) Prototipação.

A primeira etapa (reflexiva/imersiva) tem por finalidade analisar os programas de aprendizagem de cada componente curricular, definindo as habilidades e atitudes que se quer que o aluno alcance. Para tal, foram propostas questões norteadores para conduzir a discussão e a concretização da etapa: $\mathrm{O}$ que queremos que os alunos saibam? Quais as aprendizagens? O que ele estará apto a executar/praticar? Quais as competências que desenvolveu?

Para a sistematização da reflexão proposta nessa primeira etapa, apresentamos o Jogo de Ideias. A atividade foi desenvolvida por meio do ambiente on-line Jamboard (http://jamboard.google.com). Este ambiente foi selecionado pois permite a inserção de notas usando o modelo de post-its. O uso de post-its é adequado, pois facilita a seleção e a organização das ideias, deixando evidente os termos em alta e os mais recorrentes na etapa proposta. Além disso, possibilita a síntese, uma vez que o espaço para a escrita é reduzido. A Figura 3 mostra o resultado da atividade Jogo de Ideias. 
IX Congresso Brasileiro de Informática na Educação (CBIE 2020)

Anais do XXXI Simpósio Brasileiro de Informática na Educação (SBIE 2020)

Figura 3 - Jogos de Ideias

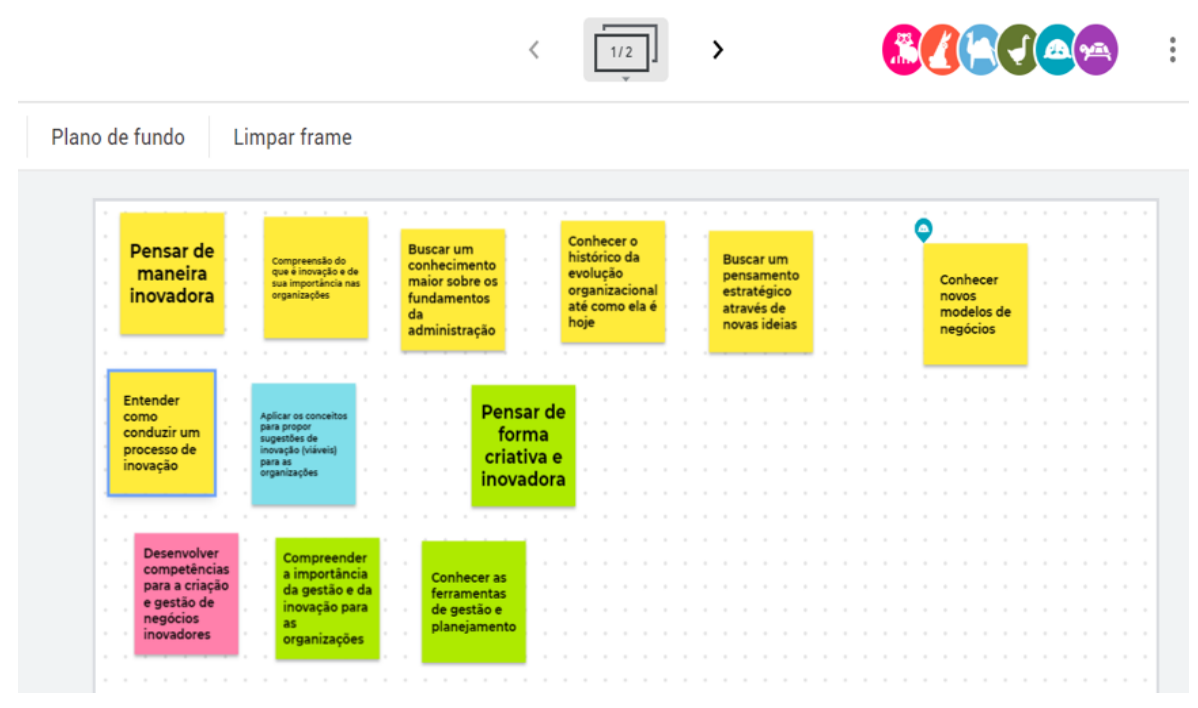

Fonte: acervo das autoras (2020)

A etapa 2 tem por finalidade a ideação do planejamento, de forma a definir as competências, por meio de objetivos de alta e baixa complexidade ${ }^{2}$, a fim de visualizar o módulo de aprendizagem em uma perspectiva macro.

A atividade consiste em organizar as ideias da etapa 1 em um conjunto de competências. A Figura 4 apresenta a sistematização das competências propostas pelos professores a partir do Jogo de Ideias. Os post-its na parte inferir da imagem (coloridos de cor-de-rosa) representam as competências propostas para o módulo.

Figura 4 - Construção das competências

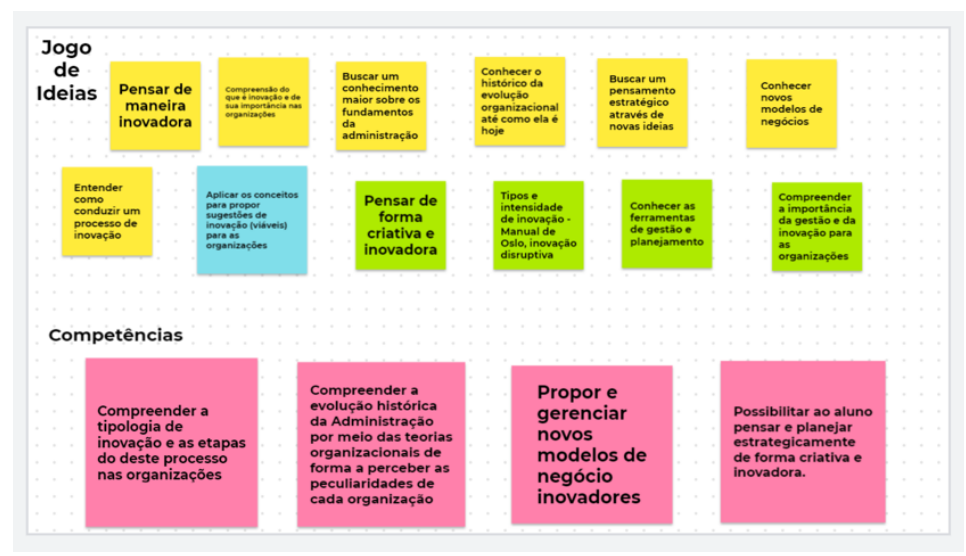

Fonte: acervo das autoras (2020)

Por fim, a etapa 3 tem por objetivo consolidar a organização dos módulos. Para isso, a proposta prevê o uso de uma matriz Canvas (Figura 5).

\footnotetext{
${ }^{2}$ Conforme taxonomia (BLOOM et al., 1956)
} 
Essa terceira etapa tem por objetivo traduzir as competências, bem como os conhecimentos/programas de aprendizagem, em carga horária, com o intuito destas se desdobrarem em disciplinas/blocos/saberes, na perspectiva de um currículo híbrido. Cabe ressaltar, que a instituição de ensino onde a proposta foi validada, indicou que o currículo deveria seguir a regra de ter ao menos $40 \%$ de sua carga horária total na modalidade a distância. Desta forma, os módulos poderiam alternar sua carga horária, considerando a regra posta.

Figura 5 - Matriz de Canvas

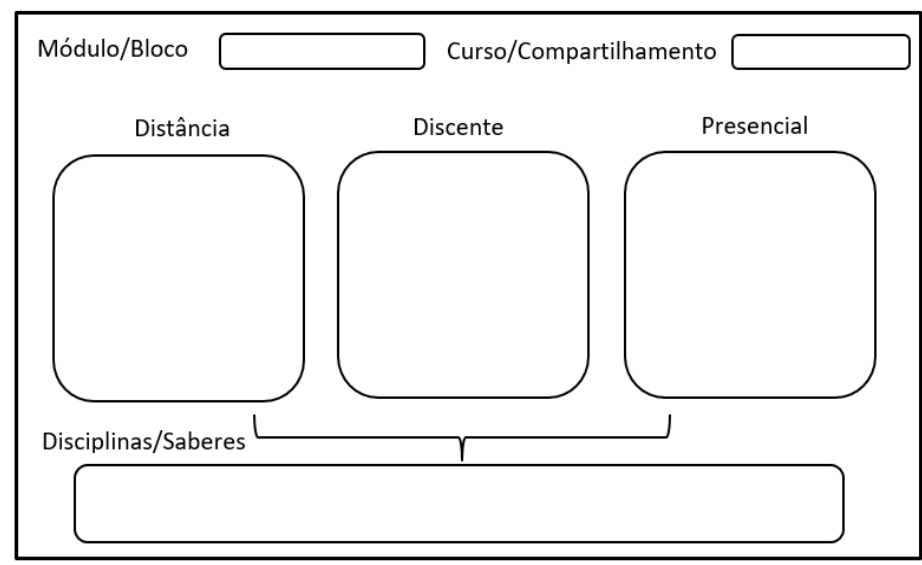

Fonte: elaborado pelas autoras (2020)

Para conduzir a organização das competências em carga horária no módulo, foram estabelecidos alguns critérios de presencialidade, ou seja, critérios para orientar a necessidade (ou não) de atividades presenciais. São estes: a) atividades presencias em laboratórios; b) explorar a sala de aula como um espaço de metodologiaa e aprendizagens ativas; c) conhecimentos aplicados; d) construções compartilhadas de conhecimentos; e) práticas laboratoriais (espaços/desensalamento). A Figura 6 apresenta duas propostas idealizadas pelos docentes para a distribuição de carga horária.

Figura 6 - Validação da terceira etapa

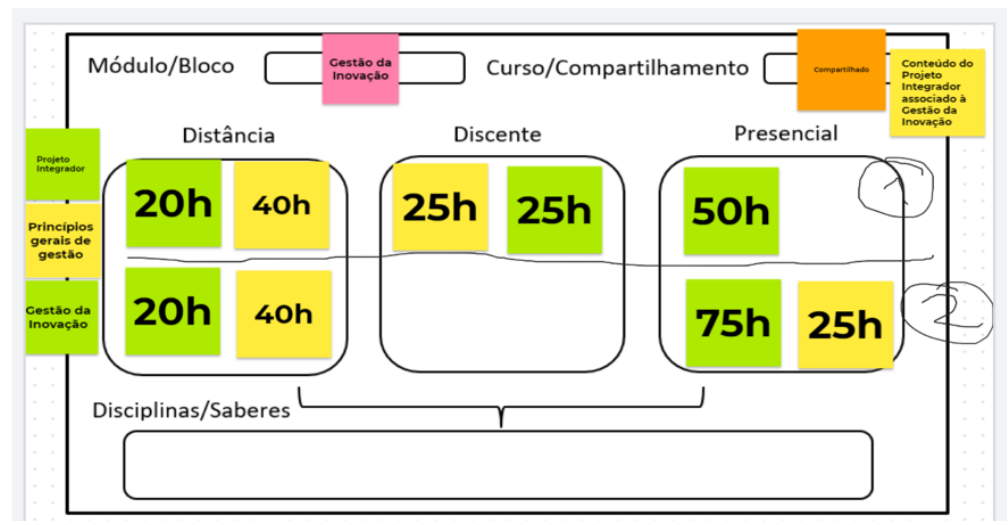

Fonte: acervo das autoras (2020)

Após a finalização da etapa 3, os professores puderam visualizar toda a construção do módulo, a partir de competências, com a devida distribuição da carga horária, na perspectiva de um currículo híbrido. 
IX Congresso Brasileiro de Informática na Educação (CBIE 2020)

Anais do XXXI Simpósio Brasileiro de Informática na Educação (SBIE 2020)

\section{Discussão}

Partindo do objetivo de desenvolvimento de uma proposta para auxiliar os docentes na elaboração de módulos de aprendizagem, com base na aprendizagem por competências, organizamos três etapas para a condução do processo. As ferramentas, Microsoft Teams e Jamboard, utilizadas para condução da validação no contexto on-line, se mostraram ágeis e adequadas.

A ferramenta Jamboard da Google, foi utilizada para sustentar o registro das etapas 1 e 2, uma vez que a validação aconteceu a distância. Entretanto, considerando-se as possibilidades de interação e colaboração, sugere-se que a ferramenta também possa ser utilizada em contexto presencial. Entretanto, também é possível reproduzir a atividade com o uso de matrizes impressas.

Na primeira etapa, foi possível visualizar a lógica de pensamento dos professores na distribuição de habilidades e atitudes. Esta primeira etapa, que se aproxima da etapa de imersão do DT, é o cerne de todo o processo, pois faz com o que sujeito reflita quanto ao problema lançado, bem como pense no público-alvo em questão. A técnica proposta para o Jogo de Ideias, a partir de questões norteadoras, busca conduzir a reflexão para a análise do problema e do público-alvo.

Já na segunda etapa, que compreendeu a concepção do módulo a partir da definição das competências, corroborou com a proposta e se mostrou assertiva ao processo validado. A elaboração das competências, usando uma proposta visual, permitiu analisar os conhecimentos e as aprendizagens necessárias de forma transversal e interdisciplinar no módulo.

Por fim, na etapa três, foi possível a visualização do resultado do processo que vinha sendo construído ao longo das etapas anteriores. A prototipação, etapa do DT que, neste estudo, foi realizada em uma matriz de Canvas, se mostrou eficiente, pois foi possível visualizar o módulo de aprendizagem de forma a abranger todos componentes e suas respectivas cargas horárias, o que facilitou o planejamento do mesmo e também de verificar o currículo total de graduação de forma macro.

\section{Considerações Finais}

A partir da validação do processo proposto e organizado em três etapas, foi possível compreender como a metodologia irá se comportar, qual a percepção dos docentes, bem como sua adequação para a condução na perspectiva de planejamento curricular.

Verificamos que o uso de técnicas do DT e da matriz de Canvas, aliadas à proposta de DA, têm potencial para sustentar a atividade proposta. O processo desenvolvido auxiliou os professores na proposição do módulo, permitindo ajustes no processo de construção, sempre que preciso. O registro das competências de forma visual também se mostrou relevante e, várias vezes, os professores voltaram para esta etapa para refletir sobre a articulação dos conteúdos e carga horária. Portanto, o processo proposto permite uma constate (re)adaptação durante o planejamento.

Por fim, compreende-se a importância da validação deste processo para o seguimento da pesquisa. Entendemos que a validação com apenas um pequeno grupo consiste em uma limitação do estudo. Entretanto, a próxima etapa da pesquisa envolve 
um refinamento da proposta e ampliação do detalhamento, de forma a focar nos diferentes componentes curriculares, além de ampliar o escopo de validação.

\section{Referências}

BASSANI, Patrícia Scherer. Documentação de atividades de aprendizagem com uso de tecnologias. In $3^{\circ}$ Congresso Brasileiro de Informática na Educação, 2014. Anais... Disponível em: <https://www.br-ie.org/pub/index.php/pie/article/view/3155> Acesso em: 11 dez. 2019

BASSANI, Patricia. Scherer; REIS, Carla; FARIA, P. H. Pedro. Ambientes colaborativos para a produção e o compartilhamento de atividades de aprendizagem: análise dos ambientes WebCollage, LDshake e ILDE. RENOTE. REVISTA NOVAS TECNOLOGIAS NA EDUCAÇÃO, v. 17, p. 1-10, 2019.

BASSANI, Patricia. B. Scherer; REIS, A. N.; DALANHOL, D. R. Análise da colaboração em ambientes digitais para compartilhamento de atividades de aprendizagem: uma perspectiva com base em Learning Design In: 27o Simpósio Brasileiro de Informática na Educação - SBIE, 2016, Uberlândia. Anais do XXVII Simpósio Brasileiro de Informática na Educação (SBIE 2016). Porto Alegre: Sociedade Brasileira de Computação - SBC, 2016.

BASSANI, Patricia. B. Scherer; LIMA, C. C. ; DALANHOL, D. R. Documentação e compartilhamento de atividades de aprendizagem: um estudo sobre repositórios de prática e artefatos de mediação. Revista e-Curriculum (PUCSP), v. 14, p. 1423-1453, 2016.

BLOOM, B. S. et al. Taxonomy of educational objectives. New York: David Mckay, 1956. 262 p. (v. 1)

CAVALCANTI, Carolina Costa; FILATRO, Andrea. Design Thinking na educação presencial, a distância, e corporativa. São Paulo: Saraiva, 2016.

CONOLE, Grainne. Designing for learning in an open world. UK: Springer, 2013

DRESCH, Aline; LACERDA, Daniel Pacheco; ANTUNES, José Antonio Valle Jr. Design Science Research: método de pesquisa para avanço da ciência e tecnologia [recurso eletrônico] /. - Porto Alegre: Bookman, 2015.

LARNACA. Declaration on Learning Design. Disponível em: $<$ https://larnacadeclaration.wordpress.com/> Acesso em: 31 jul 2020.

NITZSCHE, Rique. Afinal o que é design thinking? São Paulo: Edições Rosari, 2012.

RUIZ, Cristiane Regina. Criação de um modelo Canvas para planejamento acadêmico aliado a ferramentas de Design Thinking. Revista on line de Política e Gestão Educacional, Araraquara, v. 23, n. 2, p. 321-327, maio/ago., 2019. E-ISSN:1519-9029. DOI: $10.22633 /$ rpge.v23i2.11762

SANTOS, Gabrielle dos; BASSANI, Patrícia B. S. Métodos e ferramentas para o processo de planejamento docente no contexto dos estudos da área de Design da Aprendizagem. RENOTE. REVISTA NOVAS TECNOLOGIAS NA EDUCAÇÃO, v. 18, p. 1-10, 2020.

ZABALA A.; ARNAU L. Métodos para ensinar competências. Porto Alegre: Penso, 2007. 